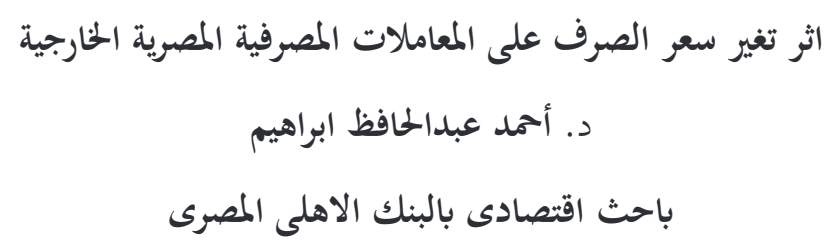

$$
\begin{aligned}
& \text { الملتخص } \\
& \text { تلعب التغيرات الكبيرة في سعر الصرف دورا اساسيا في زيادة المخاطر التي يواجهها المستوردين والمصدرين، ويكون لذلك تأثير كبير } \\
& \text { علي السياسات الاقتصادية للدولة. لذا فان هذه الدراسة استخدمت المنهج التحليلي في توضيح اثر سعر الصرف علي المعاملات المصرفية } \\
& \text { الخارجية في مصر خلال الفترة (1986- 2017)، وكيفية الوصول للتوازن في سعر الصرف والمعاملات المصرفية الخارجية، والاهتمام } \\
& \text { بدراسة سعر الصرف والمعاملات المصرفية الخارجية وتوضيح تأثنر الاول علي الثاني. معرفة التغيرات التي تحدث في الصادرات البنكية } \\
& \text { والواردات البنكية النابتحة عن التغيرات التي تحدث في نظام سعر الصرف المصري. } \\
& \text { وتوصلت الدراسة للنتائج الاتية: } \\
& \text { • هناك علاقة عكسية بين سعر الصرف والصادرات البنكية، بمعني إذا زاد سعر الصرف تقل الصادرات البنكية وهذا يؤثر بالسالب علي } \\
& \text { ميزان المدفوعات أي يحدث عجز .وإذا حدث العكس فإنه يحدث فائض في الميزان التجاري البنكى. } \\
& \text { هناك علاقة عكسية بين الواردات البنكية وسعر الصرف، وهذا علي عكس العلاقة الطبيعية بين الواردات البنكية وسعر الصرف وقد } \\
& \text { يرجع ذلك إلي عوامل أخري تؤثر علي الواردات البنكية بخلاف سعر الصرف. وتوجد العلاقة العكسية بين الواردات البنكية وسعر } \\
& \text { الصرف في حالة السلع الكمالية وهذا يخالف القاعدة العامة التي تنص علي "أن هناك علاقة طردية بين سعر الصرف والواردات البنكية" } \\
& \text { وهذا ما يحدث في السلع الضرورية مثل القمح. } \\
& \text { إن سعر الصرف يؤثر علي الميزان التجاري البنكى. }
\end{aligned}
$$

\title{
Abstract:
}

The significant changes in the exchange rate play a key role in increasing the risks faced by importers and exporters; this has a significant impact on the economic policies of the state. Therefore, the study used the analytical method to clarify the effect of the exchange rate on the balance of trade in Egypt during the period (1986 - 2017), how reach to balance in exchange rate and balance of trade, focusing on studying exchange rate and balance of trade and clarify the influence of first on the second, and knowing the changes that happen in exports and imports which results from the changes that happen in Egyptian exchange rate system.

This study reaches to the following results:

- There is negative relation between exchange rate and exports. This means that the more exchange rate is, the less exports are. And this influence negatively on balance of payment which leads to deficit and when the verse happens there is surplus in balance of trade.

- There is negative relation between imports and exchange rate; this is in contrast with the natural relation between imports and exchange rate because of other factor which influence on imports. This negative relation exists in case of luxury goods which is opposite of public role which provided that "There is positive relation between imports and exchange rate" and this happens in case of essential goods like wheat.

- Exchange rate influence on balance of trade. 
المقدمة:

تعد التقلبات في اسعار صرف العملات ذات اهمية بالغة باعتبارها حلقة ربط بين الاقتصادات الدولية ومقياسا لحجم معاملتها بالاضافة المى ذلك له تأثير واضح على التوازن الكلي للاقتصاد من خلال علاقته المباشرة والغير المباشرة بلمتغيرات الاقتصادية الكلية وخصوصا الميزان التجاري البنكى متمثلا في التعاملات الخارجية بالصرف. ويعتبر سعر الصرف احد المؤشرات الاقتصادية والمالية التى تعبر عن جودة الاداء الاقتصادي لاى دولة, ويمثل سعر الصرف العمود الفقرى الذى تعتمد عليه اقتصاديات اى دولة من دول العالم سواء كانت من الدول المتقدمة او النامية لذلك تسعى معظم الحكومات إلى انتهاج سياسات تحدف إلى ضمان استقرار سعر صرف عملاتحا لتجنيب دولها التقلبات الحادة التي تمر هها العملات من فترة لأخرى، ويتعاظم هذا الدور في الدول النامية لأن معظم هذه الدول تعاني من انفتاح اقتصادياتا بشكل كبير ومن عجز أكبر في ميزان مدفوعاها،ما بيجعلها أشد تأثرا بالتقلبات الاقتصادية الدولية، وأكثر عرضه للأزمات والمشاكل الخارجية، مماينعكس سلبا على درجة الاستقرار المحلي فيه. ويعرف ميزان المدفوعات لاى دولة على انه عبارة عن سجل تاريخى للمعاملات الاقتصادية الدولية مع بقية دول العالم. ويعتبر الميزان التجارى هو المؤشر الذى يقيس مجمل الفرق بين قيمة الصادرات البنكية وقيمة الواردات البنكية الخاصة بالمعاملات البنكية سواء بحركة رؤوس الاموال او التحويلات البنكية او قيمة الصادرات والواردات في الدولة وهو احد مكونات ميزان المدفوعات . تؤثر تغيرات سعر الصرف الاجنبى على الميزان التجارى بحيث ان ارتفاع سعر الصرف العملة المحلية للدولة يؤدى الى ارتفاع الاسعار النسبية لسلعتها المحلية الامر الذى يؤدى لارتفاع اسعار صادراتا مقارنة باسعار ورادتا من السلع الاجنبية. كذلك فان ارتفاع سعر الصرف

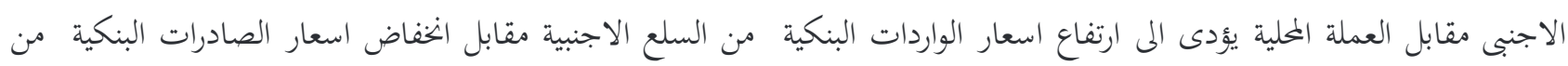
السلع المحلية وهذا يؤدى الى اختلال شروط التبادل التجارى. وشهد سعر الصرف والمعاملات المصرفية الخارجية المصري تطورات عديدة للاسباب التالية حرب اليمن ومصر، والحربين العربية الاسرائيلة التي كانت في السبعينيات ادت الي خسارة العملات الصعبة مما ادي تبني سياسة الباب المفتوح من اجل الحفاظ علي نمو مرتفع حتي منتصف الثمانينيات، ولكن هذا لم يساعد علي تحقيق الانتعاش الاقتصادي مما ترتب عليه انخفاض معدل الصادرات البنكية خلال تلك الفترة. وتم تطبيق برنامج التحرير المالي والذي ادي الي حدوث استقرار نسبي في سعر صرف الجنيه المصري في عام 1998 حتي بعد ماساة الاقصر في عام 1997 التي نتج عنها تدهور كبير في حصيلة البلاد من الصرف الاجنبي. وفن عام 2003 اعلن عن تعويم الجنيه المصرى والتخلى عن نظام ربط العملات والانتقال الى سعر الصرف الذى يتحدد بناء على العرض والطلب وبالتالى الخفض الجنيه المصرى.

في عام 2008 بسبب الازمة المالية العالمية التي اثرت على سعر الصرف سلبا وادت الى انخفاض حركة التبادل وكذلك تدفق رؤوس الاموال الاجنبية. وفي 2011/2010 شهدت مصر ثورة 25 يناير حيث اثرت سلبا على حركة التجارة والاستثمار والسياحة وانخفاض معدلات التشغيل والانتاج والناتج المحلي الاجمالي وادى ذلك الى عجز ميزان المدفوعات. وفي 2017 ارتفع العجز في المعاملات 
المصرفية الخارجية نتيجة لتراجع حاصلات الصادرات البنكية السلعية الناتجة عن الخفاض اسعار البترول العالمية ثم وزيادة الكميات المعروضة منه.

\section{فكرة البحث:}

يعتبر من اهم الموضوعات التي تحتاج الي تحليل نظرا لما نتج عن التغيرات الاخيرة في سعر صرف الجنيه المصري من تغيرات على المستوى الكلى للاقتصاد المصرى . الاهتمام بدراسة سعر الصرف والمعاملات المصرفية الخارجية وتوضيح تأثير كلا منهما على الاخر.

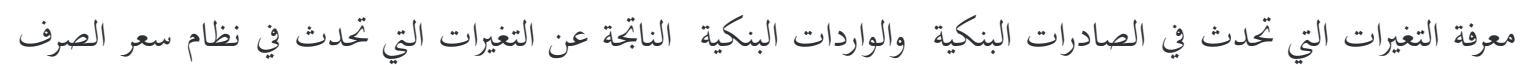
المصري واثر ذلك على ميزان المدفوعات في الفترة (2017-1986) كيفية الوصول للتوازن في سعر الصرف والمعاملات المصرفية الخارجية .

مشكلة البحث:

هل عندما تحدث تغيرات في سعر الصرف يؤثر ذلك علي المعاملات المصرفية الخارجية ما يؤدى إلى العجز فن الميزان التجارى ومن تم التغير في شكل المقتصد لذلك ثثمثل المشكلة فن دراسة أثثر تغير سعر صرف الجنيه المصري بالنسبة للدولار الأمريكي علي المعاملات المصرفية الخارجية المصري

الدراسات السابقة:

\begin{tabular}{|c|c|c|c|}
\hline \multicolumn{4}{|c|}{ اولا: الدراسات العبية } \\
\hline النتائج التى اوصت بما & المدف من الدراسة & اسم المؤلف وعنوان الدراسة & s \\
\hline 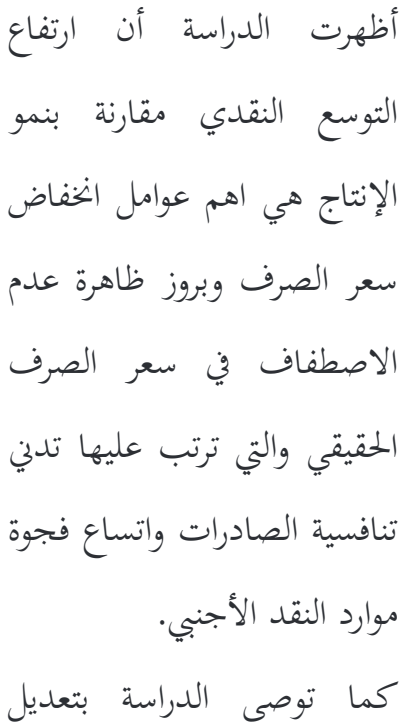 & 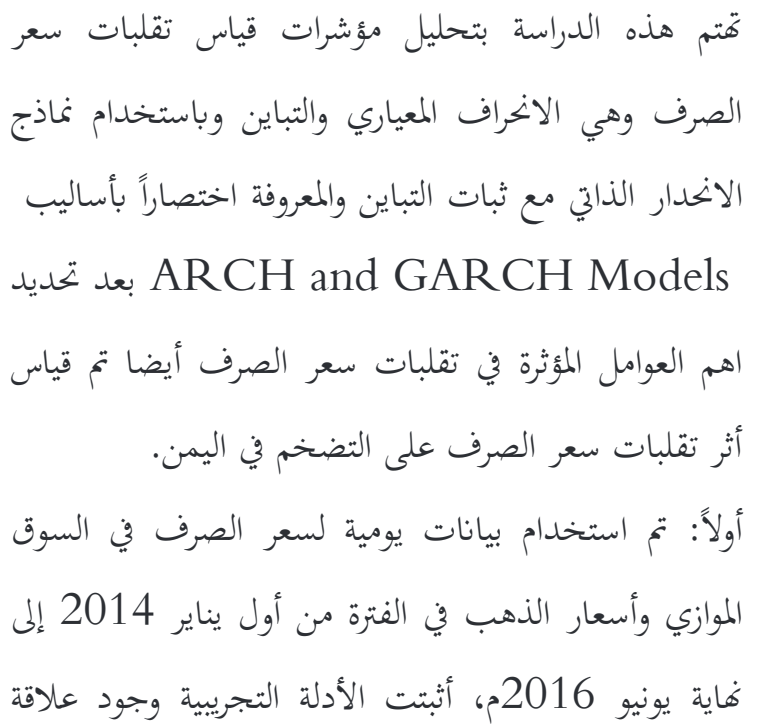 & (2016-1990) دراسة اليامنة، الدواي، اثن & 1 \\
\hline
\end{tabular}




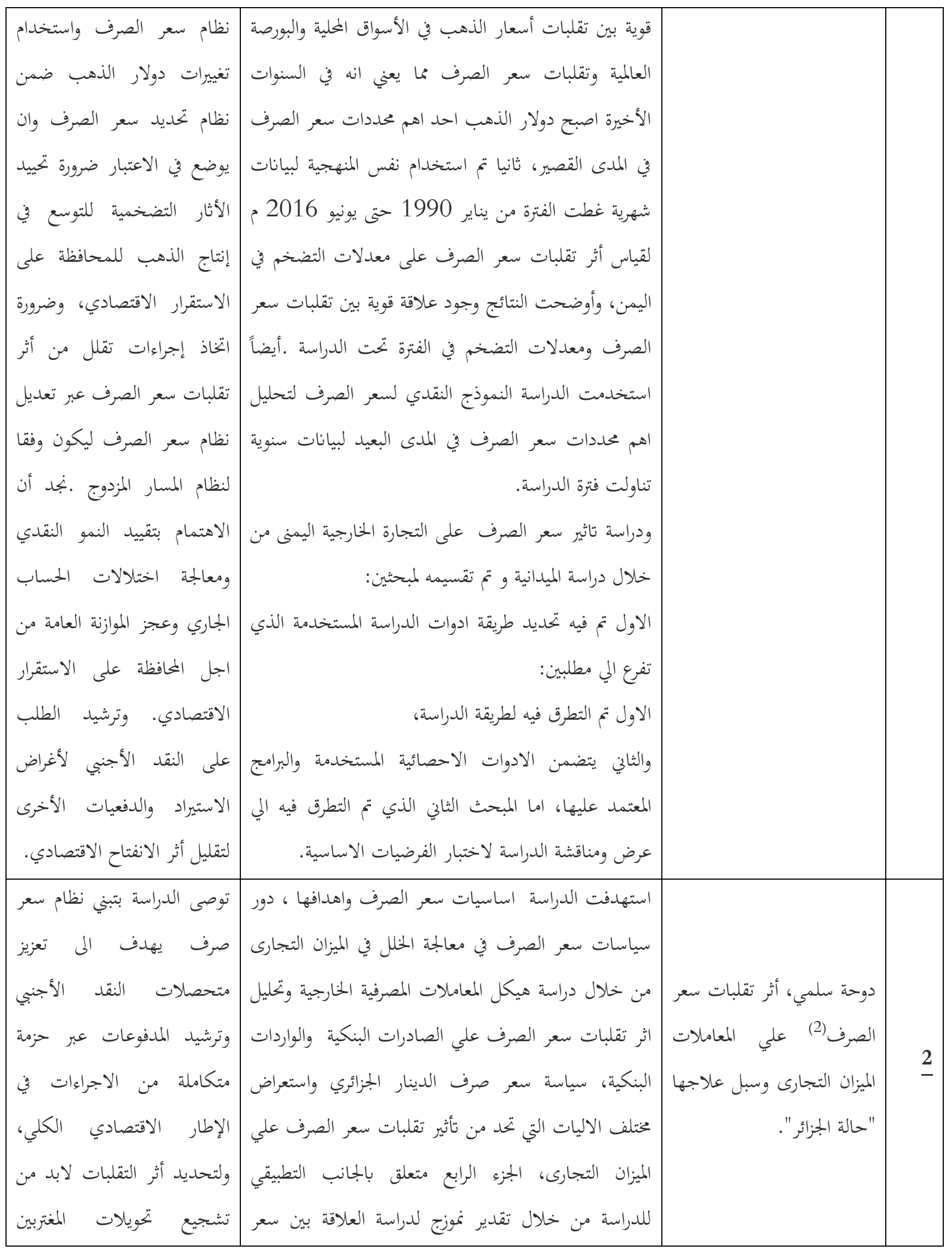




\begin{tabular}{|c|c|c|c|}
\hline وتشجيع الاستثمارات الأجنبية. & الصرف الدينار الجزائري ورصيد الميزان التجارى خلال الفترة & & \\
\hline 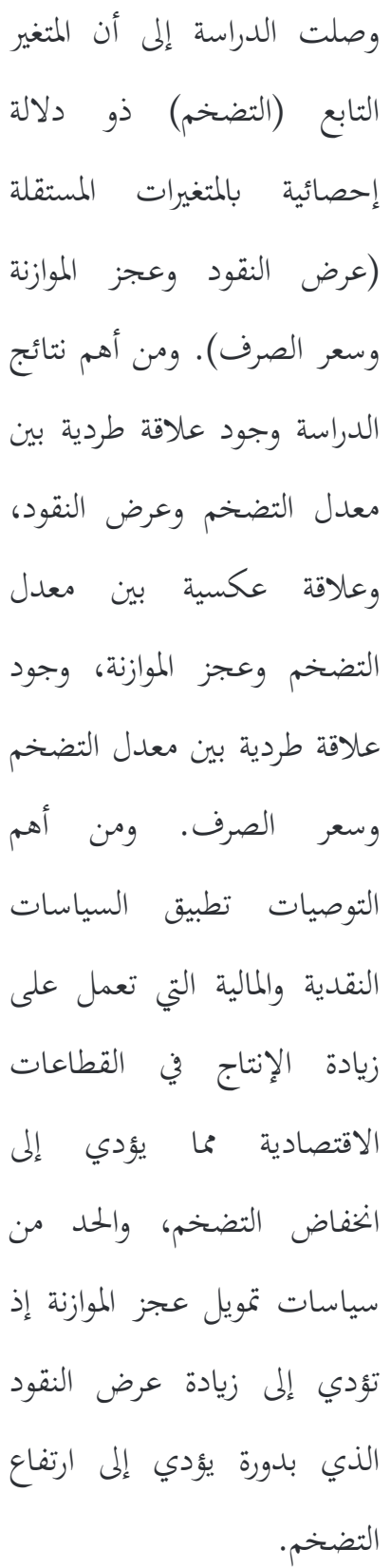 & 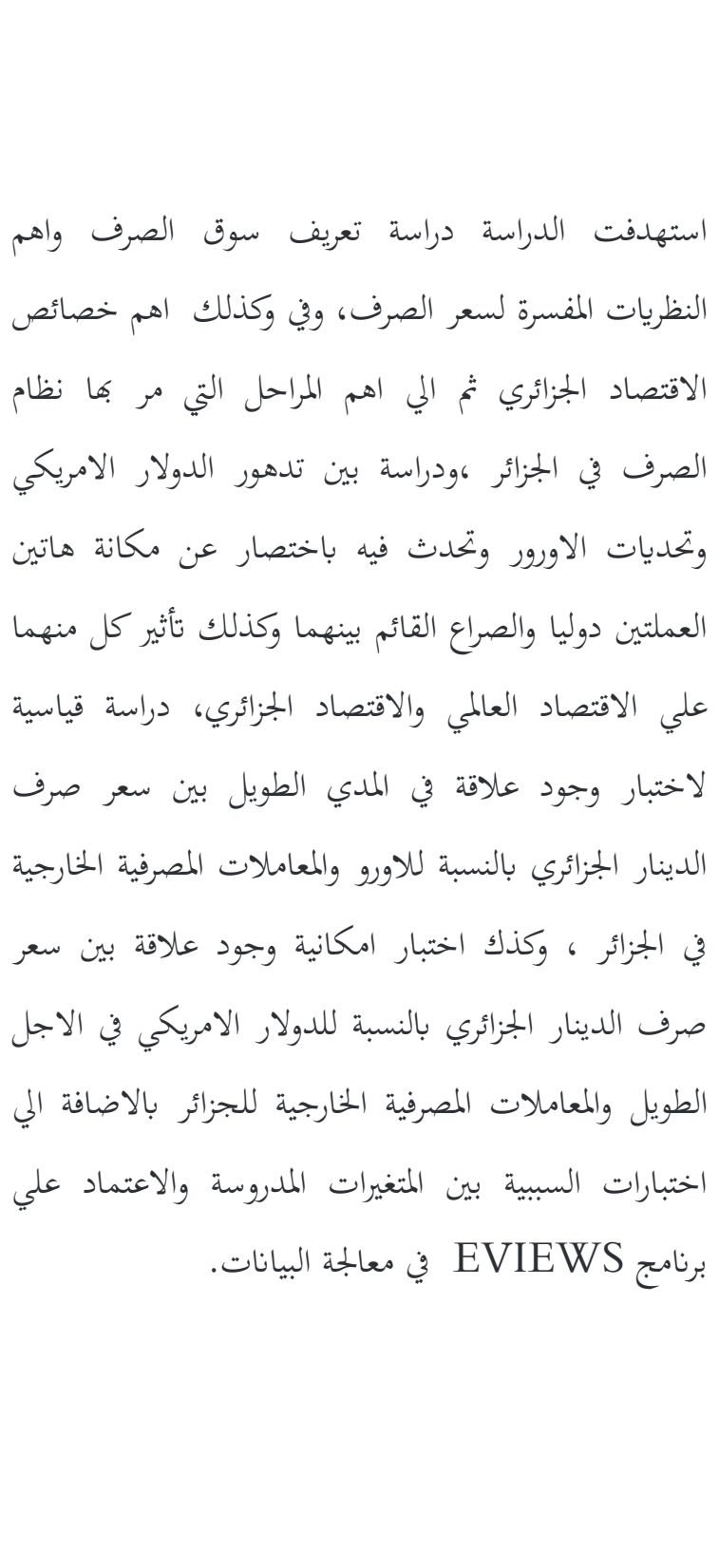 & التجاري البنكى & 3 \\
\hline
\end{tabular}

ثانيا : الدراسات الاجنبية 


\begin{tabular}{|c|c|c|c|}
\hline النائج اختبار لاقرانج إلى عدم وجود ترابط ذاتي & 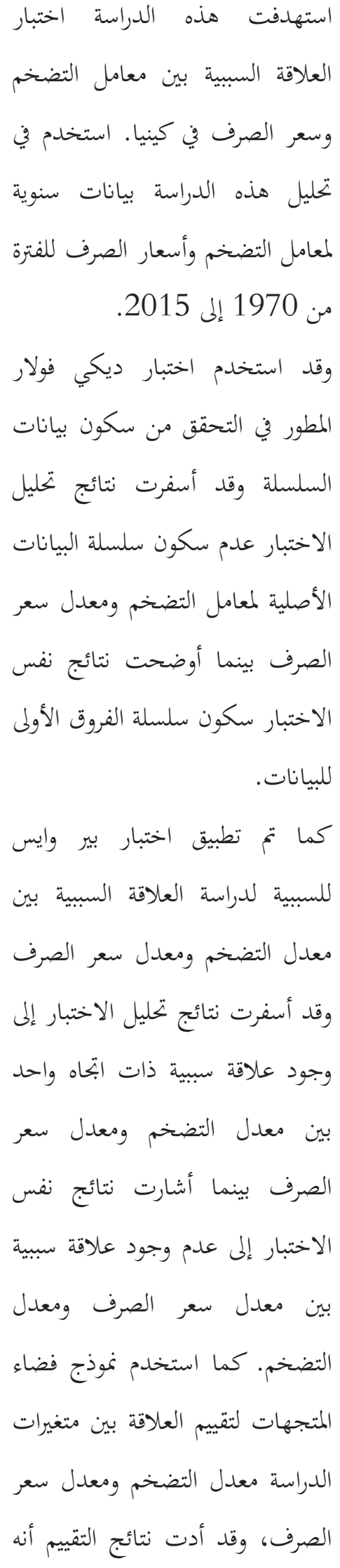 & $\begin{array}{l}\text { Osoro Cliff }{ }^{(1)} \& \\
\text { Ogeto Willy, } \\
\text { MACRO } \\
\text { ECONOMIC } \\
\text { FLUCTUATIONS } \\
\text { EFFECTS ON THE } \\
\text { FINANCIAL } \\
\text { PERFOMANCE OF } \\
\text { LISTED } \\
\text { MANUFACTURING } \\
\text { FIRMS IN KENYA }\end{array}$ & 4 \\
\hline
\end{tabular}

\footnotetext{
${ }^{(1)}$ Osoro Cliff \& Ogeto Willy, MACRO ECONOMIC FLUCTUATIONS EFFECTS ON THE FINANCIAL PERFOMANCE OF LISTED MANUFACTURING FIRMS IN KENYA
} ‘the International Journal of social Science . Vol.21 NO.1, 2014. 


\begin{tabular}{|c|c|c|c|}
\hline & بناء العملى معايير اختيار رتبة النماذج & & \\
\hline 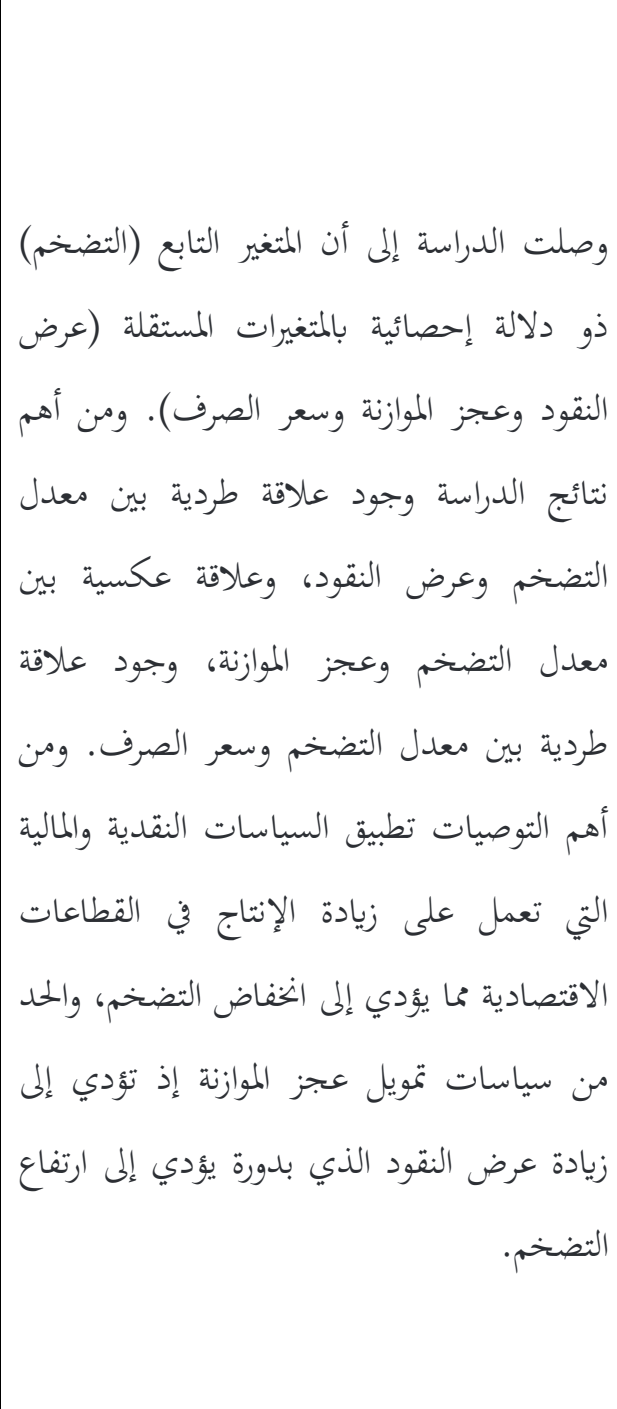 & 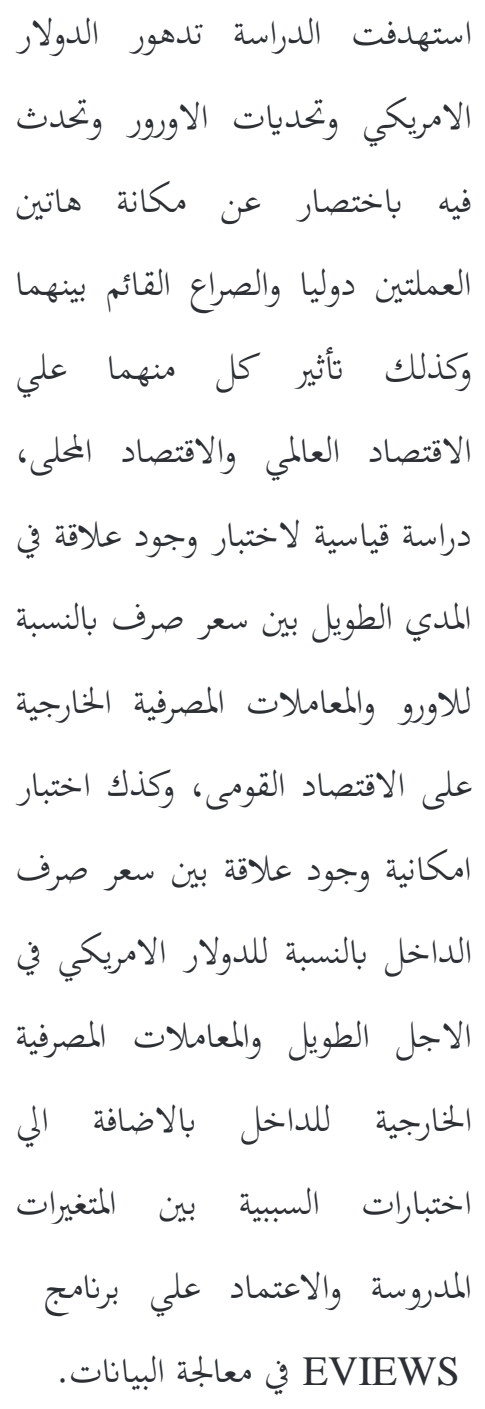 & $\begin{array}{l}\text { MBUBI }^{(1)} \text { AMOS } \\
\text { MBITHI 'The Effect } \\
\text { of Foreign Exchange } \\
\text { Rates On The } \\
\text { Financial } \\
\text { Performance Of } \\
\text { Firms Listed At The } \\
\text { Nairobi Securities } \\
\text { Exchange. }\end{array}$ & $\underline{5}$ \\
\hline من من خلال دراسة متوسط نصيب الفرد من الناتج الإجمالي للدول العشترين الأوائل اقتصادياً & لالاهم الدول وجد إنماسلى الناتج المحلى بالنسبة الولايات المتحدة & $\begin{array}{l}\text { Ng }{ }^{(2)} \text { Yuen-Ling, Har } \\
\text { Wai-Mun, Real } \\
\text { Exchange Rate and } \\
\text { Trade Balance } \\
\text { Relationship: An } \\
\text { Empirical Study on }\end{array}$ & $\underline{6}$ \\
\hline
\end{tabular}

${ }^{(1}$ MBUBI AMOS MBITHI ،The Effect of Foreign Exchange Rates On The Financial Performance Of Firms Listed At The Nairobi Securities Exchange, Master Thesis ‘Business Administration ،UNIVERSITY OF AIROBI, 2002.

${ }^{(} \mathrm{Ng}$ Yuen-Ling, Har Wai-Mun, Real Exchange Rate and Trade Balance Relationship: An Empirical Study on The most countrie, International Journal of Business and Management, Vol. 3, No. 8, p130-137, 2008. 


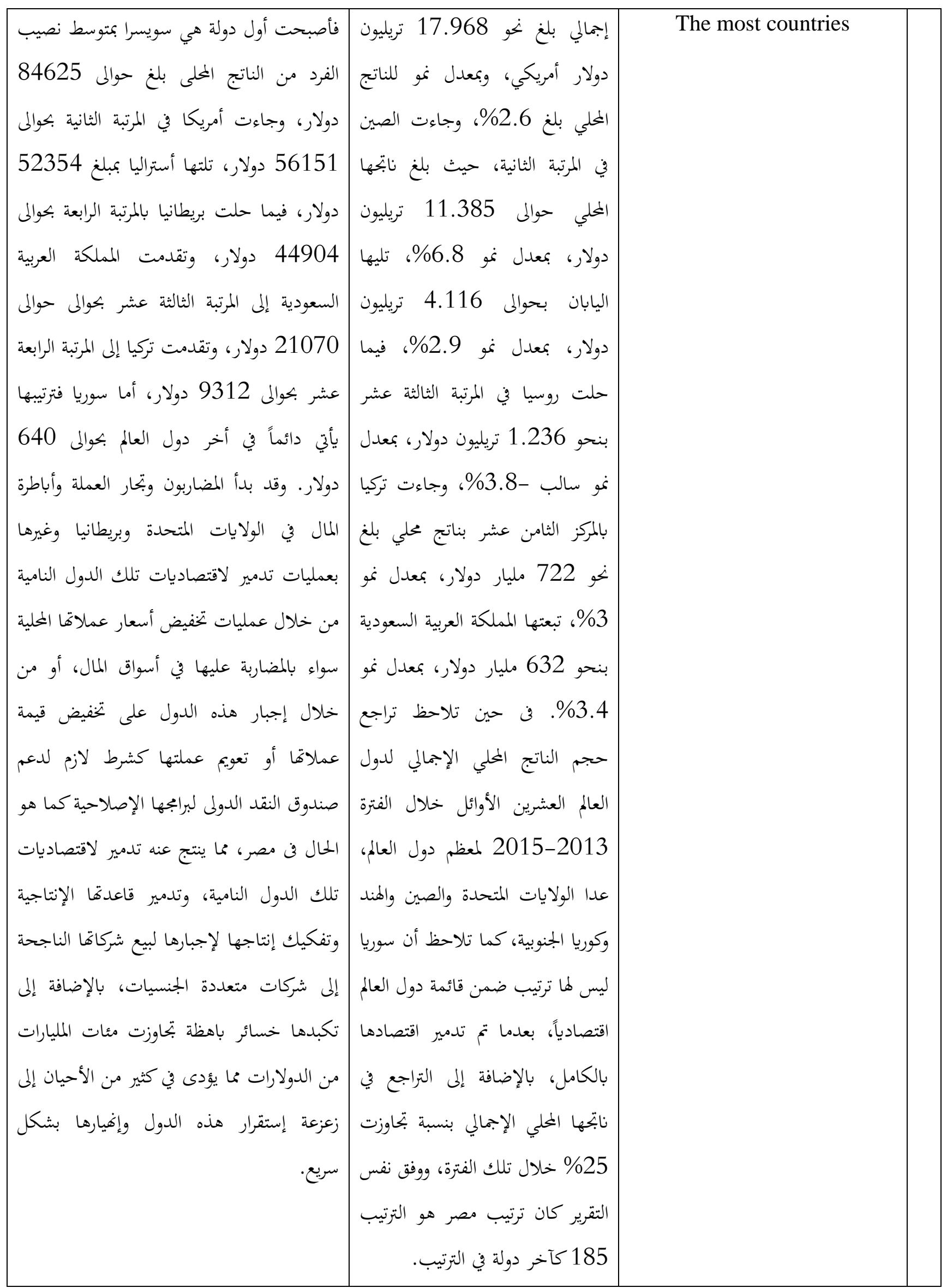




\begin{tabular}{|c|c|}
\hline نتائج & نتائج الدراسة الحالية \\
\hline 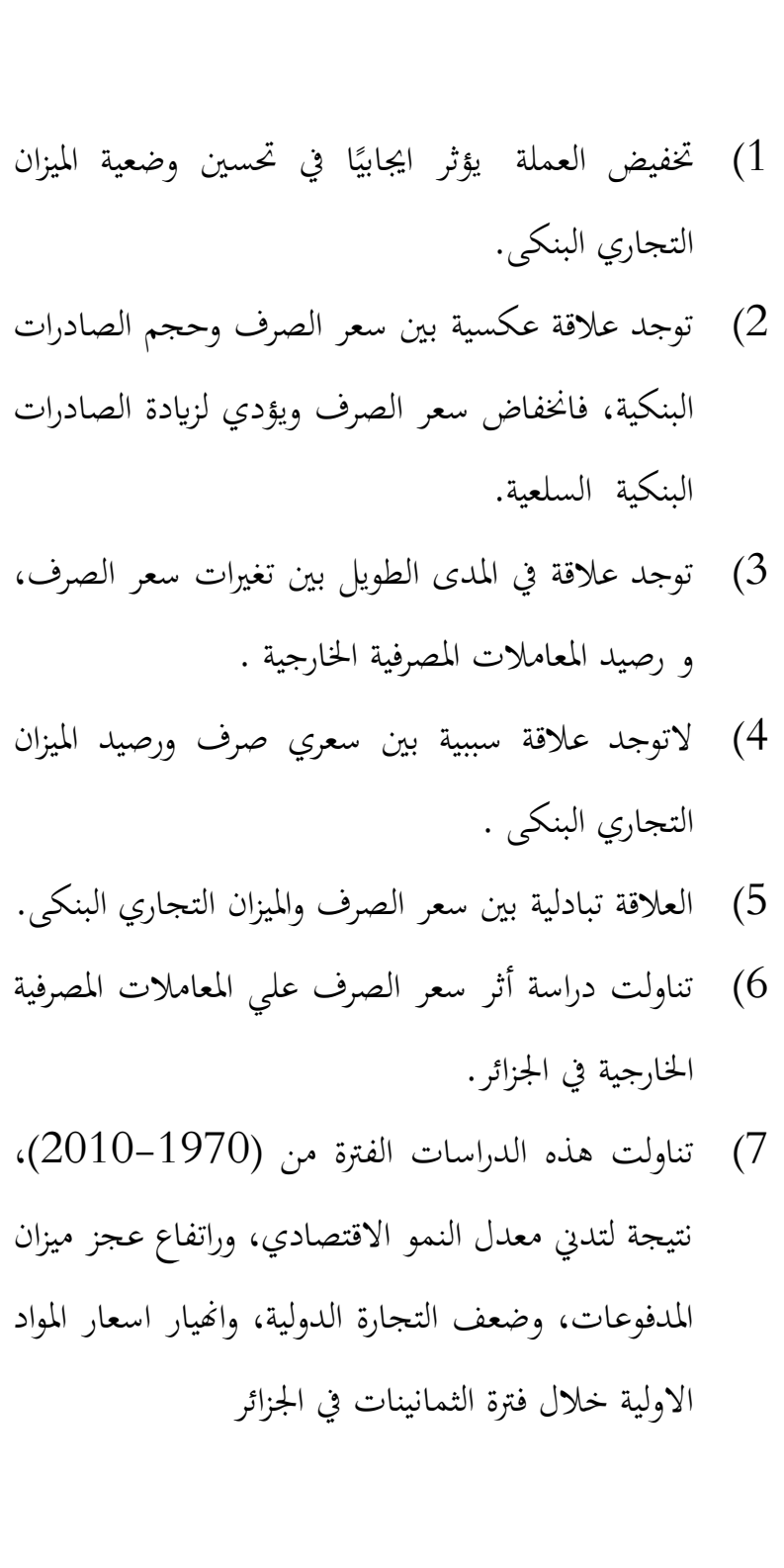 & 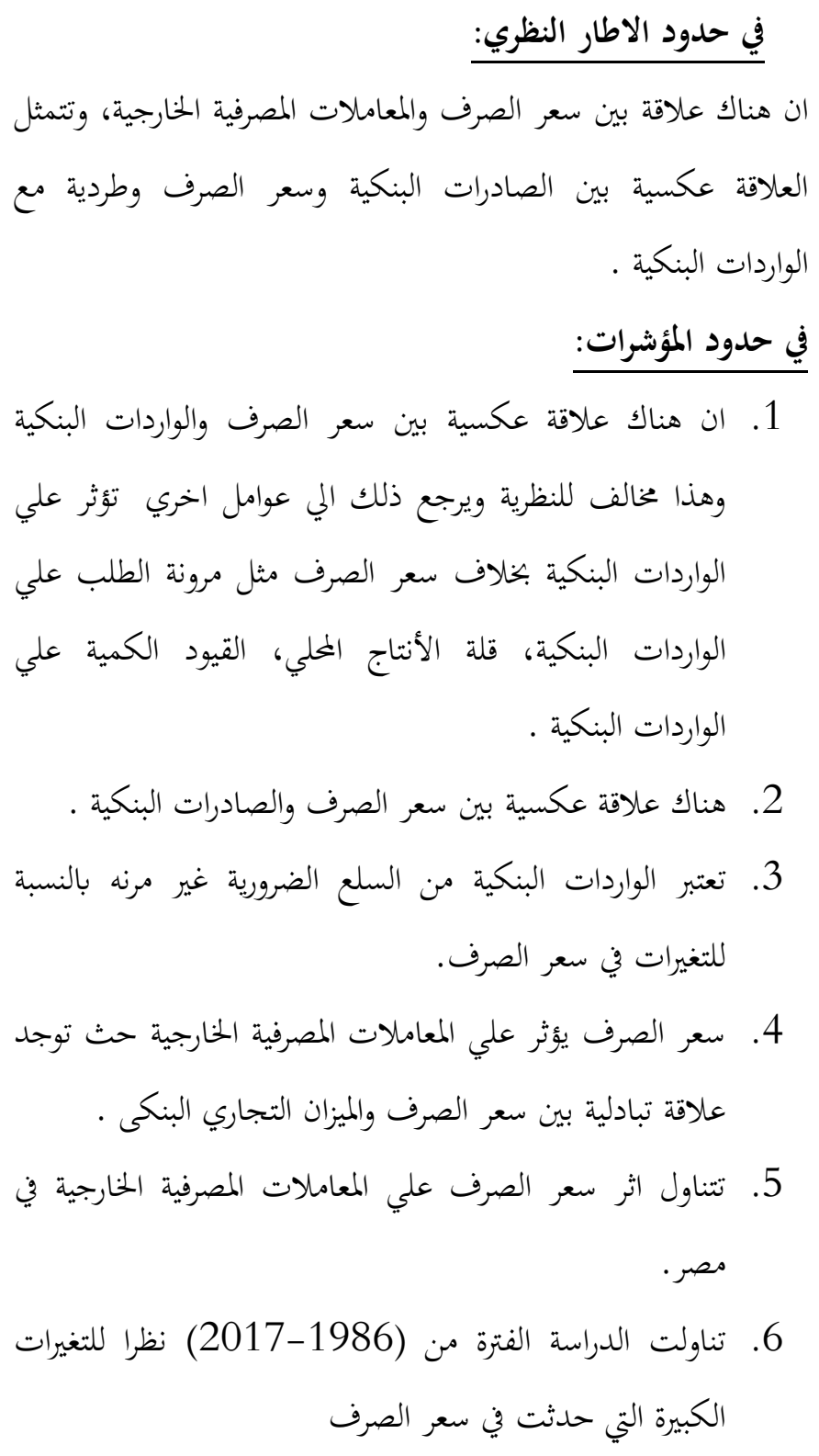 \\
\hline
\end{tabular}

$$
\text { 1- أهداف الدراسة }
$$

معرفة التغيرات التي تحدث في الصادرات البنكية والواردات البنكية الناتحة عن التغيرات التي تحدث في نظام سعر الصرف المصري.

$$
\text { • - توضيح مدى تأثير سعر الصرف على المعاملات المصرفية الخارجية . }
$$

• دراسة اثر التغيرات والأزمات الحادثة خلال فترة الدراسة (1986 - 2017) والتي أثرت على النشاط الاقتصادي بشكل عام

$$
\begin{aligned}
& \text { وسعر الصرف المعاملات المصرفية الخارجية بشكل خاص في مصر. } \\
& \text { 3- فرضيات البحث }
\end{aligned}
$$




\section{• ان هناك فروق معنوية ذات دلالة احصائية بين سعر الصرف والمعاملات المصرفية الخارجية . • ان هناك فروق معنوية ذات دلالة احصائية بين الصادرات البنكية وسعر الصرف. • ان هناك فروق معنوية ذات دلالة احصائية بين الواردات البنكية وسعر الصرف.}

ان هناك فروق معنوية ذات دلالة احصائية لبعض العوامل والمتغيرات المؤثرة على الإستثمارات الحقيقية فن مصر في ضوء تعويم سعر الصرف

\section{4- حدود الدراسة}

لقد حددت الدراسة في اطار مكاني وزمني حيث تم حصر الدراسة في جمورية مصر العربية من اجل توضيح اثر تغيرات سعر الصرف على المعاملات المصرفية الخارجية ، اما من حيث الاطار الزمني فقد حصرت الدراسة المؤشرات الزمنية في جمهورية مصر العربية في الفترة الزمنية

(1986- 2017).

\section{5- منهجية الدراسة}

من اجل دراسة موضوع البحث، وتحليل ابعادها وجوانبها ونتائجها، تم استخدام بمموعة من الادوات التحليلية للاجابة علي تساؤل البحث واثبات صحة الفرضيات لذلك تم استخدام الاسلوب النظري في الجزء الاول، والاسلوب الوصفي التحليلي في الجزء الثاني. نتائج البحث ومناقشتها

أولا: أثر سعر الصرف على الميزان التجاري البنكى يعتبر سعر الصرف المرآة التي ينعكس عليها مركز الدولة التجاري مع العالم الخارجي ويظهر ذلك من خلال العلاقة بين الصادرات البنكية والواردات البنكية، فاستيراد السلع من احدى البلدان الاجنبية يزيد من الطلب على عملة هذا البلد في السوق الوطني بمعنى ان الواردات البنكية تزيد من الطلب على العملات الاجنبية وتزيد من عرض العملة الوطنية في اسواق العالم، ولكن الصادرات البنكية تزيد من الطلب الاجنبي على العملة الوطنية وتزيد من عرض العملات في السوق الوطني مما يؤدي المى حدوث اختلال في المعاملات المصرفية المنارجية لمذه الدولة ويتم معالجة هذا الاختلال من خلال التخاذ سياسات سعر الصرف التي تتناسب مع حالة الاقتصاد الوطني. ويتكون هذا الجزء من مبحثين: (1) n

المبحث الاول يوضح اثر سعر الصرف على المعاملات المصرفية الخارجية من حيث (اثر تقلبات سعر الصرف على الصادرات البنكية والواردات البنكية، العلاقة بين سعر الصرف والميزان التجاري البنكى )، اما المبحث الثاني يوضح تطورات سعر الصرف والمعاملات المصرفية الخارجية خلال فترة البحث والاسباب التي ادت الى تلك التطورات.

\section{المبحث الاول: اثر سعر الصرف علي الميزان التجاري البنكى}

يظن البعض بأن المعاملات المصرفية الخارجية لا يرتبط بسعر صرف العملة المحلية ولكن ما تم التحقق منه أن هناك علاقة وثيقة ما بين سعر صرف العملات المحلية والمعاملات المصرفية الخارجية , ويرجع ذلك إلي إن كل دولة لا تطبق التحديد الإداري وتتبع نظام الصرف

اولا: تأثير تقلبات سعر الصرف علي الصادرات البنكية تقلب سعر الصرف يقصد به : " تخفيض قيمة العملة الوطنية بالنسبة للعملات الاجنبية او رفعها , ويساهم هذا التقلب في احداث تغيرات في اسعار السلع المحلية بالنسبة للاسعار في الدول الاجنبية ، في حالة تخفيض قيمة العملة المحلية تنخفض اسعار السلع المحلية في 
الخارج نتيجة لزيادة المعروض النقدي في الداخل (تخفيض الطلب علي العملة وصادرات الدولة) وزيادة حجم الواردات البنكية من الخنارج، فيؤدي ذلك الي ارتفاع حجم الصادرات البنكية، ويحدث العكس في حالة ارتفاع قيمة العملة المحلية وهذا يوضح العلاقة العكسية بين سعر الصرف والصادرات البنكية .

ثانيا: ثأثير تقلبات سعر الصرف علي الواردات البنكية يؤثر سعر الصرف علي الواردات البنكية، في حالة انخفاض قيمة العملة المحلية يؤدي ذلك الي ارتفاع الصادرات البنكية وانخفاض حجم الواردات البنكية ويرجع ذلك الي انخفاض اسعار السلع المحلية وزيادة المعروض النقدي وانخفاض الطلب علي السلع الأجنبية. اما في حالة ارتفاع قيمة العملة المحلية نتيحة لزيادة الصادرات البنكية وارتفاع الطلب علي السلع المحلية ،ينخفض المعروض النقدي في الداخل نتيجة لزياده الطلب علي السلع المحلية وترتفع الاسعار المحلية مما يؤدي ذلك الي زيادة حجم الواردات البنكية وهذا يوضح العلاقة الطردية بين سعر الصرف والواردات البنكية .

ثالثا: العلاقة بين سعر الصرف والميزان التجاري البنكى

شكل رقم (1) : مخطط لبيان العلاقة بين سعر الصرف والمعاملات المصرفية الخارجية في حالة العجز:

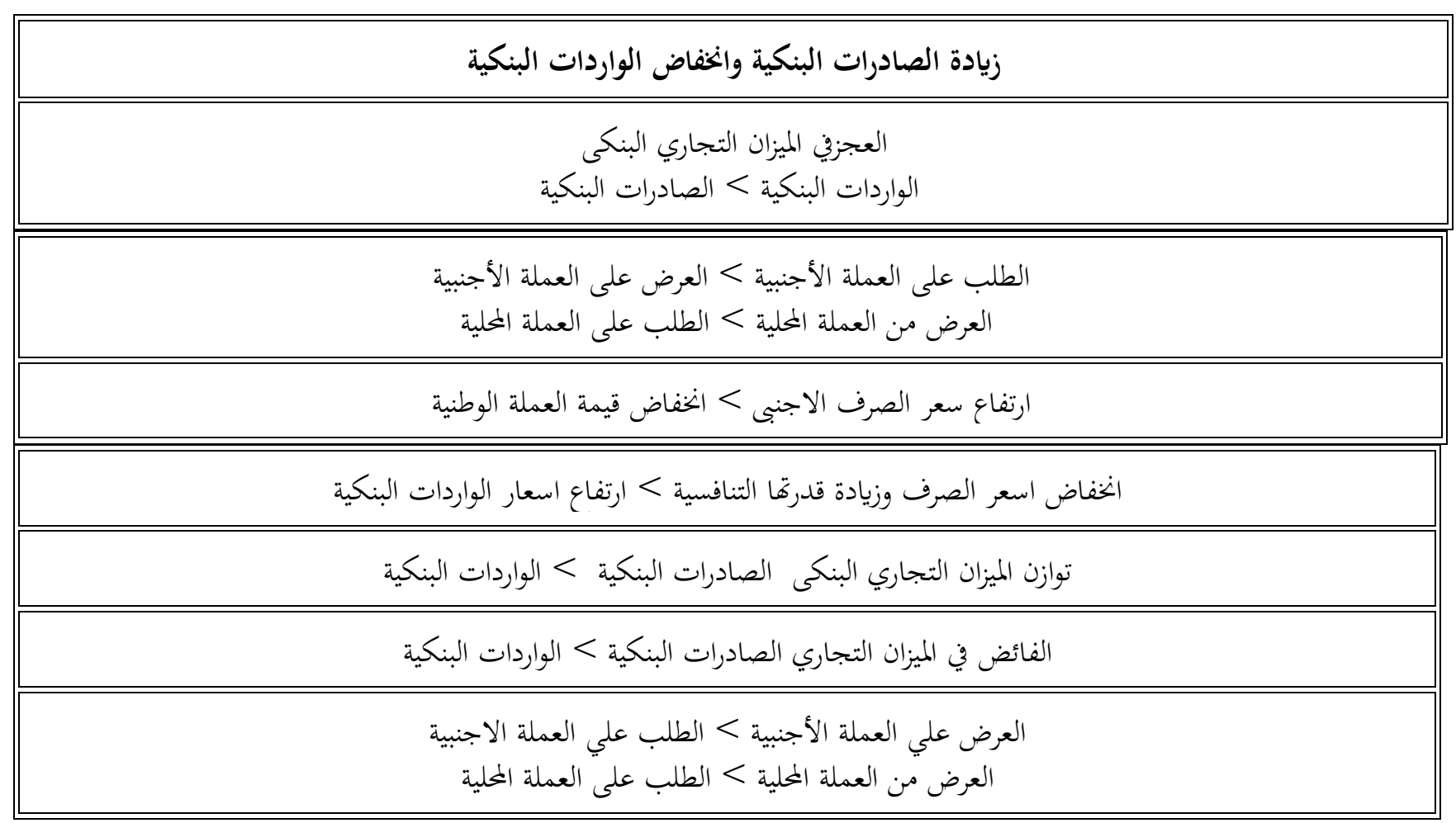

المصدر: دكتور ايهاب محمد صبرى، محاضرات في الاقتصاد الدولى، معهد منظمة التجارة الدولى، القاهرة 2017 ص 51.

شكل رقم (2): مخطط لبيان العلاقة بين سعر الصرف والمعاملات المصرفية الخارجية في حالة الفائض

توازن الميزان التجاري البنكى البكى البكية

الواردات البنكية > الميزان البحادي البنكىات البنكية

ارتفاع اسعار الصادرات البنكية > وانخفاض قدرتحا التنافسية

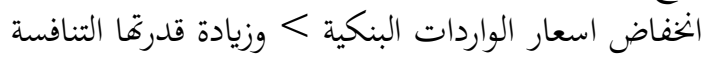

انخفاض الصادرات البنكية > ارتفاع الواردات البنكية 


\section{انخفاض سعر الصرف الاجنبى > ارتفاع قيمة العملة الوطنية}

المصدر : دكتور ايهاب محمد صبرى، محاضرات في الاقتصاد الدولى، معهد منظمة التجارة الدولى، القاهرة 2017 ص 87.

من خلال الرسم السابق يتضح ان هناك علاقة تبادلية بين سعر الصرف والميزان التجاري البنكى، وان الهدف الاساسى هو تحقيق التوازن في المعاملات المصرفية الخارجية.

المبحث الثاني: تطورات سعر الصرف والمعاملات المصرفية الخارجية واسبابها نظرا لقوة العلاقة بين سعر الصرف والمعاملات المصرفية الخارجية تم اتخاذ مؤشرات سعر الصرف والمعاملات المصرفية الخارجية والصادرات البنكية والواردات البنكية والممثلة في حركة رؤوس الاموال والتعاملات التجارية خلال الفترة (1986-2017) من اجل دراسة اثر سعر الصرف على كل منها ويتضح ذلك في الآتي:

جدول (1): بيان برصيد المعاملات المصرفية الخارجية في مصر من (1986-2017)

\begin{tabular}{|c|c|c|c|c|c|c|c|}
\hline صادرات التجاري البنكى الميزان & $\begin{array}{c}\text { واردات السلع والحدمات من إجمالي الناتج } \\
\text { الملحملي) }\end{array}$ & صن صادرات السلع & السنة & - رصيد الميزان & واراردات السلع & 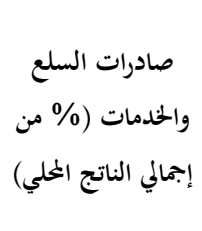 & السنة \\
\hline-4.85085 & 22.33064 & 17.47979 & 2002 & -12.1273 & 32.04153 & 19.91428 & 1986 \\
\hline-4.35471 & 22.67089 & 18.31618 & 2003 & -9.86286 & 25.59443 & 15.73157 & 1987 \\
\hline-2.58683 & 24.38323 & 21.79641 & 2004 & -10.2076 & 22.76629 & 12.55871 & 1988 \\
\hline-1.35998 & 29.58994 & 28.22996 & 2005 & -17.8427 & 35.16113 & 17.31839 & 1989 \\
\hline-2.26555 & 32.6091 & 30.34355 & 2006 & -14.4579 & 32.3514 & 17.89348 & 1990 \\
\hline-1.61891 & 31.56872 & 29.94981 & 2007 & -12.6657 & 32.71329 & 20.0476 & 1991 \\
\hline-4.57841 & 34.82814 & 30.24973 & 2008 & -7.98009 & 35.79569 & 27.8156 & 1992 \\
\hline-5.59464 & 38.63763 & 33.04299 & 2009 & -2.51618 & 30.91301 & 28.39684 & 1993 \\
\hline-6.6398 & 31.59662 & 24.95682 & 2010 & -4.25258 & 30.09021 & 25.83763 & 1994 \\
\hline-5.23786 & 26.5871 & 21.34925 & 2011 & -5.48571 & 28.05714 & 22.57143 & 1995 \\
\hline-4.12078 & 24.68821 & 20.56743 & 2012 & -5.14706 & 27.69608 & 22.54902 & 1996 \\
\hline-8.00435 & 24.58047 & 16.57612 & 2013 & -5.449 & 26.19878 & 20.74978 & 1997 \\
\hline-6.3944 & 23.56546 & 17.17106 & 2014 & -6.05491 & 24.89658 & 18.84167 & 1998 \\
\hline-8.54465 & 22.97921 & 14.43456 & 2015 & -9.49896 & 25.71329 & 16.21434 & 1999 \\
\hline-8.1881 & 22.10712 & 13.91902 & 2016 & -8.25748 & 23.30949 & 15.05202 & 2000 \\
\hline-8.44102 & *21.64787 & 13.20685 & 2017 & -6.6157 & 22.81682 & 16.20112 & 2001 \\
\hline
\end{tabular}

http://data.albankaldawli.org المصدر : قاعدة بيانات البنك الدولي 
شكل رقم : 3) بيان برصيد المعاملات المصرفية الخارجية في مصر من (1986-2017) صادر ات السلع و الخدمات (\% من إجمالي الناتج المحلي)

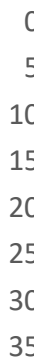

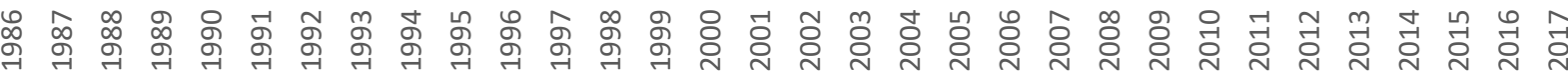
صادر ات السلع والخدمات (\% من إجمالي الناتج المحلي) -

المصدر : جدول رقم (1)

جدول رقم (2) : بيان بالعلاقة بين سعر الصرف وكلا من الصادرات البنكية والواردات البنكية في مصر من (1986-2017)

\begin{tabular}{|c|c|c|c|c|c|c|c|}
\hline سعر الصرف الرسمي & 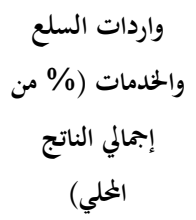 & 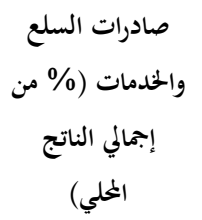 & السنة & سعر الصرف & 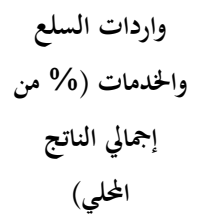 & والحدادرات السلع (إمالي الناتج من & السنة \\
\hline 3.97253 & 22.33064 & 17.47979 & 2002 & 0.700001 & 32.04153 & 19.91428 & 1986 \\
\hline 4.499667 & 22.67089 & 18.31618 & 2003 & 0.700001 & 25.59443 & 15.73157 & 1987 \\
\hline 5.850875 & 24.38323 & 21.79641 & 2004 & 0.700001 & 22.76629 & 12.55871 & 1988 \\
\hline 6.196242 & 29.58994 & 28.22996 & 2005 & 0.700001 & 35.16113 & 17.31839 & 1989 \\
\hline 7.778833 & 32.6091 & 30.34355 & 2006 & 0.866667 & 32.3514 & 17.89348 & 1990 \\
\hline 6.733167 & 31.56872 & 29.94981 & 2007 & 1.552362 & 32.71329 & 20.0476 & 1991 \\
\hline 6.635433 & 34.82814 & 30.24973 & 2008 & 3.138008 & 35.79569 & 27.8156 & 1992 \\
\hline 8.432235 & 38.63763 & 33.04299 & 2009 & 3.321748 & 30.91301 & 28.39684 & 1993 \\
\hline 10.544553 & 31.59662 & 24.95682 & 2010 & 3.352518 & 30.09021 & 25.83763 & 1994 \\
\hline 12.621943 & 26.5871 & 21.34925 & 2011 & 3.385133 & 28.05714 & 22.57143 & 1995 \\
\hline 15.932828 & 24.68821 & 20.56743 & 2012 & 3.392208 & 27.69608 & 22.54902 & 1996 \\
\hline 16.056058 & 24.58047 & 16.57612 & 2013 & 3.391483 & 26.19878 & 20.74978 & 1997 \\
\hline 16.870325 & 23.56546 & 17.17106 & 2014 & 3.38875 & 24.89658 & 18.84167 & 1998 \\
\hline 20.077609 & 22.97921 & 14.43456 & 2015 & 3.38875 & 25.71329 & 16.21434 & 1999 \\
\hline 17.689548 & 22.10712 & 13.91902 & 2016 & 3.39525 & 23.30949 & 15.05202 & 2000 \\
\hline 17.691258 & 21.64787 & 13.20685 & 2017 & 3.47205 & 22.81682 & 16.20112 & 2001 \\
\hline
\end{tabular}

http://data.albankaldawli.org المصدر : قاعدة بيانات البنك الدولي 
ينخفض منحني الصادرات البنكية في الفترة مابين (1986-1988) من 19.9 الي 17.3، ثم بدأ منحني الصادرات البنكية في الارتفاع في الفترة مابين (1988-1992) من 17.3 الي 28.3. ثم نجد ان الصادرات البنكية انخفضت في الفترة مابين (19921999) من 28.3 الي 15.05. ثم ارتفاع الصادرات البنكية في الفترة مابين (1999-2005) من 15.05 الي 30.3. ثم يوضح الشكل في الفترة ما بين (2005-2007) ثبات نسبي في منحنى الصادرات البنكية ، وبعد ذلك يبدأ منحنى الصادرات البنكية في الزيادة من 30.2 المى 33 من عام 2007 حتى عام 2008، ثم يأخذ المنحنى فن الانخفاض مابين (2008-2017)، حيث تقل قيمة الصادرات البنكية من 33 الم 15.0.

ب- بالنسبة للواردات البنكية

يبدأ منحنى الواردات البنكية بالانخفاض في الفترة مابين (1986-1987) من 32.04 الي 22.7.ثم ارتفعت الواردات البنكية في الفترة مابين (1987-1988) من 22.7 الي 35.16، ثم تنخفض الواردات البنكية في الفترة مابين (1988-1989) من 35.16 الي 32.35. ثم تعود للارتفاع مرة اخرى في الفترة (1991-1989) من 32.35 الي 35.7. ثم الخفضت الواردات البنكية في الفترة (1991-2001) من 35.7 الي 22.33. ونجد بعد ذلك ان المنحنى بدأ في الارتفاع في الفترة (2001-2005) من من 22.33 الي 32.60. ثم انخفاضه ما بين عامى (2005 : 2006). ثم أخذالمنحنى في الزيادة بدءاً من عام 2006 حتى عام 2008 ويعود للانخفاض مرة اخرى ما بين عامى (2008 : 2017)

شكل رقم : (4) بيان بالعلاقة بين سعر الصرف وكلا من الصادرات البنكية و الواردات البنكية في مصر من (1986-2017)

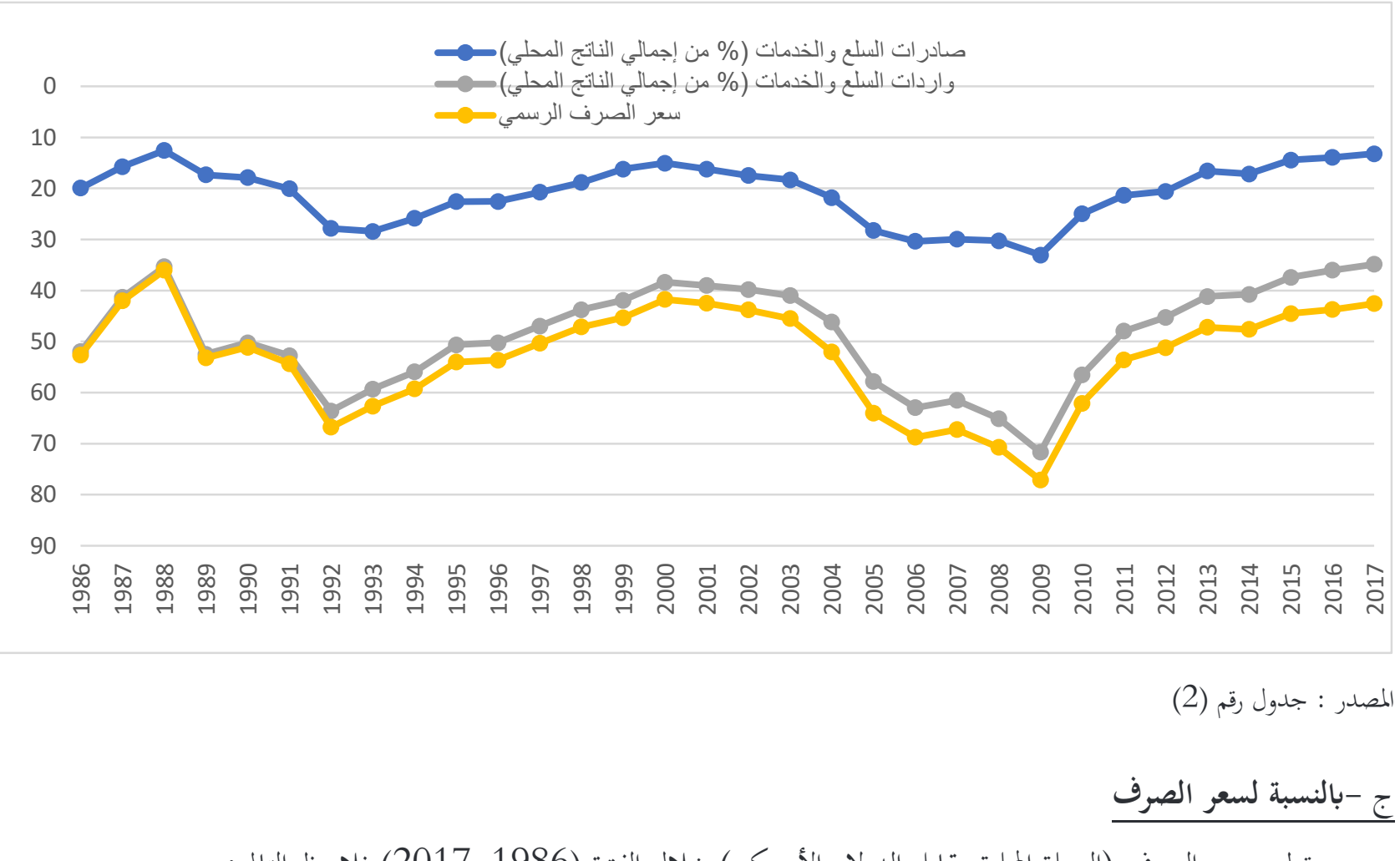

تطور سعر الصرف (العملة المحلية مقابل الدولار الأمريكي) خلال الفترة (1986-2017)ونلاحظ التالى: 
نجد ان المنحنى بدأ بثبات نسبي في الفترة (1986-1988) بمقدار 0.7001, ثم ارتفع سعر الصرف من (1988-1996) من 0.70 الي 39.39 ـ وبدأ ينخفض سعر الصرف في الفترة (1996 -1998) من 3.39 الي 3.38 .ثم ارتفع مرة اخري مابين (1998 - 2004) من 3.38 الي 6.19. انخفض سعر الصرف من 6.19 الي 5.4 في الفترة (2004 -2008)، ثم ارتفاع سعر الصرف تدريجيا من 5.43 : 7.69 خلال الفترة من 2008 الى 2017.

\section{ومن أهم الاسباب التي ادت الي ذلك التطور ما يلي: - الت 1- خلال فترة الثمانينات:}

نتيجة لحرب اليمن ومصر، والحربين العربية- الاسرائيلية في عامى(1967-1973) ، وكان ذلك عبئ ثقيلا ونتج عنه خسارة مصدرين رئيسين للدخل بالعملات الصعبة وهما ( قناة السويس وحقل سيناء النفطى)، لذلك تبنت مصر عام 1974 سياسة (الباب المفتوح) بغرض دفع عجلة النمو الاقتصادى، وتركزت هذه السياسة على الدولارات النفطية وتم الحفاظ على معدل نمو مرتفع حتى منتصف الثمانينات ولكن الجزء الاكبر من هذا النمو كان من ريع الاقتصاد الخارجى، اما الاقتصاد الداخلى فلم يطرا عليه تغيرات تذكر، لذلك بحلول عام 1986 لم يكن الانتعاش الاقتصادى الريعى المستمد قابل للاستمرار خاصة بعد تزامن اثار اهيار اسعار النفط والكساد العالمى فانخفض العائدات من النفط ورسوم قناة السويس واثر ذلك بصورة رئيسية على العملات الصعبة لذلك الخفضت الصادرات البنكية في عام 1986 ونتيجة لتلك الاختلالات اضطرت الحكومة المصرية باتباع برنامج الاصلاح عام 1987 باتفاق مع صندوق النقد الدولى الا انه تم الغاء هذا الاتفاق بعد مرور ثلاثة اشهر نظرا لعدم تمكن الحكومة من استيفاء متطلبات الصندوق واستمر تدهور الوضع الاقتصادى حتى اندلاع حرب الخليج (1990 _ 1991) وكان الاقتصاد في ذلك الوقت على وشك الاهيار حيث ارتفع العجز فن الموازنة حوالى 20\%، حيث كان هناك قدرات محدودة من الصادرات البنكية الغير نفطية. كانت فاية الحرب فرصة مباركة لمصر حيث حملت تغيرات ايجابية فن اقتصادها بسبب اتفاق دول الخليج والولايات المتحدة ونادى باريس لتقديم المساعدات المالية لمصر واعفاء جزء هام من ديوها وبالتالى التخفيف من نزيف العملات الصعبة وساعد ذلك مصر الدخول في برنامج الاصلاح الاقتصادى عام 1991. وطبقت السياسة النقدية خلال تلك الفترة نظام مايسمى اسعار الصرف المتعددة وهذا بدوره ادى الى ظهور السوق السوداء.

2- 2 خلال فترة التسعينيات:

انطلق برنامج التحرير المالى في اوائل التسعينيات وكان ذلك مع مجموعة من الاجراءات للقضاء على الكبح المالى الذى استقرت عليه السياسة النقدية والمالية منذ منتصف السبعينيات حتى فاية الثمانينات حيث حررت معدلات الفائدة وسعر الصرف ، ومن هنا بدات اجراءات اصلاح النظام. في السنة الاولى والثانية من برنامج التحرير المالى تم استبدال اشباه الضرائب المرتبطة بسياسة الكبح المالى بموارد حقيقية للتمويل مثل السندات الحكومية، فارتفعت اسعار الفائدة ومن هنا حفز ذلك تدفقات راس المال الخاص لتكون ايداعات بالنظام المصرف إو كاستثمارات ببورصة الاوراق المالية في هاية 1994 كما انه تم تطبيق برنامج الخصخصة ثم تطوير البورصة المصرية لتكون اداء فعالة في 
وكان الحصاد الاقتصادى طيبا فن مصر خلال السنوات العشر الاولى من برنامج التحرير المالى حتى بعد حدوث ماساة الاقصر عام 1997 والتى تدهورت على اثرها حصيلة البلاد من الصرف الاجنبى ،حيث كان هناك استقرار نسبى في سعر صرف الجنيه المصرى حتى عام 1998.

ويمثل عام 1991 البداية الحقيقية لاصلاح سوق الصرف الاجنبى (الاصلاح الاقتصادى) وذلك عن طريق توحيد سعر الصرف بسعر واحد مربوط بالدولار الامريكى , وتم السماح للقطاع الخاص بخدمات الصيارفة للتجارة في العملات واستمر سعر الصرف عند 3,24 جنيه للدولار حتى اواخر 1994 ثم عدل الى 3,39 جنيه للدولار واستمر ذلك حتى يونيو 2000 ووصل الى 3,41 جنيه للدولار. وبداية من التحرير المالي ارتفعت تدفقات مصر والودائع وزيادة الاحتياطات الرسمية من العملات الاجنبية حيث قدرت حجم الواردات البنكية البنكية 120.179 مليون جنيه في 1995 ، حيث بلغت 15.978 مليون جنيه سنة 1989.

\section{3- في الفترة من 2000 الى 2017:} في يوليو عام 2001 حدث ما يسمى "بأزمة العملة في مصر" ( ازمات الصرف الاجنبي ).وكان هناك استقرار نسبي في سعر صرف الجنيه المصري خلال التسعينيات ولكن مع بداية عام 1998 ظهرت بوادر ازمة العملة في مصر، وتضاعفت الازمة ووصلت ذروما في منتصف 2001، وذلك نتيجة للتعصف بقيمة الجنيه الذي فقد حوالي 70\% من قيمته في ذلك الوقت.حيث كانت البداية الحقيقية لازمة العملة في مصر في اوائل 2001 عندما اخذت العملة في الاختفاء لتظهر السوق السوداء مرة اخرى ، وعند مأساة الاقصر 1997 والاهيار الكبير في الايرادات السياحية واهيار اسعار النفط حاولت الحكومة من التخفيف من وطأة الحالة بسوق الصرف الاجنبي عن طريق الاستنزاف المستمر لاحتياطات الصرف الاجنبي والتي هبطت بصورة كبيرة من 1998 الى 2001. افقدت احداث سبتمبر 2001 بالولايات المتحدة الامريكية الاقتصاد المصري المزيد من الايرادات السياحية والتي انخفضت بصورة كبيرة بعد احداث الاقصر بعد احداث 1997. بالاضافة المى انخفاض ايرادات قناة السويس مع تصاعد انذار الحرب في منطقة الشرق الاوسط ونتيجة لذلك عملت الصادرات البنكية السلعية على تغطية نصف الواردات البنكية ، وبذلك ارتفعت السوق السوداء وفي 2003 اعلن عن تعويم الجنيه المصري والتخلى عن نظام ربط العملات الذي كان معمولا به منذ برنامج التحرير المالي في مصر والانتقال اللى سعر صرف يتحدد وفقا للعرض والطلب وبالتالي انخفاض قيمة الجنيه ليصل الى 5.40 جنيه ولعبت التوقعات باندلاع حرب العراق منذ منتصف 2002 حتى نشوب الحرب في 2003 (غزو امريكا للعراق) دورا كبيرا في التاثير على معدلات نمو الاستثمار والتشغيل والارباح. وفي عام 2004 نتيجة لتعويم الجنيه وتخفيض قيمته ادى الى ارتفاع كبير في معدلات التضخم وهذا يرجع الى ارتفاع معدلات الواردات البنكية ـ وفف 2007 نتيجة لازمة المالية العالمية في منتصف 2007 ادى ذلك الى حدوث ازمة اخرى وهى (ارتفاع اسعار المواد الغذائية الاساسية) نتيجة لانخفاض صادرات السلع وانخفاض الايرادات فقامت الدول العربية ومنها مصر باستيراد السلع الغذائية الاساسية مثال استيراد القمح من الولايات المتحدة الامريكية. وفي عام 2008 من ابرز الاحداث التي اثرت على سعر الصرف هي الازمة المالية العالمية عام 2008، وتتمثل البداية الحقيقية للأزمة في امريكا عام 2007 ـ وامتدت هذه الازمة المى دول العالم بشكل تدريجى بحكم الترابط الدولى بين الدول وبذلك انخفضت حركة التبادل الدولى وتدفق روؤس الاموال الاجنبية بين دول العالم نتيجة لقيام الولايات بانخفاض صادراتما من السلع ومنها البترول وبالتالى انخفض سعر النفط العالمى لزيادة العرض من البترول خلال عامى. (2009- 2008) شهدت مصر في السنة المالية (2010- 
2011) في ثورة 25 يناير حالة من عدم الاستقرار الامنى وانعاكساته السلبية على حركة التجارة والاستثمار والسياحة والنقل وانخفاض معدلات التشغيل والانتاج والخفاض الناتج المحلى الاجمالى وقد اسفرت معاملات مصر مع العالم الخارجى خلال هذه السنة المالية عن عجز بميزان المدفوعات بلغ نو 9.8 وخلال الفترة (2012-2011) ارتفع عجز الميزان التجارى بينما استقرت حصيلة الصادرات البنكية السلعية عند مستواها السابق وانعكس ذلك علي الخفاض نسبة تخطيط حصيلة الصادرات البنكية السلعية المي المدفوعات عن الواردات البنكية السلعي اما خلال السنة المالية (2013 - 2012) كان هناك فائض كلى في ميزان المدفوعات وتراجع في عجز الميزان التجارى ويرجع ذلك اللى ارتفاع صاف التحويلات بدون مقابل بمعدل 4.7\% خلال السنة المالية(2014 -2013) ارتفع عجز الميزان التجارى نتيجة لزيادة المدفوعات عن الواردات البنكية السلعية وتراجع حصيلة الصادرات البنكية السلعية. في السنة المالية (2017-2014) ارتفع العجز فن الميزان التجارى نظرا لتراجع حصيلة الصادرات البنكية السلعية لتراجع حصيلة الصادرات البنكية البترولية النابتحة عن الخفاض اسعار البترول العالمية وزيادة الكميات المعروضة منه وفى ذلك الوقت ارتفعت المدفوعات عن الواردات البنكية السلعية بالاضافة لتراجع صافن التحويلات الجارية. من خلال الشكل رقم (4) الذي يوضح العلاقة بين سعر الصرف والصادرات البنكية وسعر الصرف والواردات البنكية في جمهورية مصر العربية، يمكن استنتاج ان هناك علاقة عكسية بين سعر الصرف والصادرات البنكية، وهناك علاقة عكسية بين الواردات البنكية وسعر الصرف.

\section{العلاقة بين سعر الصرف والمعاملات المصرفية الخخارجية:}

في حالة استيراد بلد ما فانه يتم التسديد بالعملة الأجنبية للبلد المصدر للمنتج حيث يقوم البلد المستورد بشراء العملة الأجنبية للبلد المصدر وبالتالي أي تغيير في المعاملات الاقتصادية يودى إلي تغيير في سعر الصرف، وفى حاله عجز ميزان المبادلات الجارية بمعنى أن الواردات البنكية تفوق الصادرات البنكية أي أن الطلب على العملة الأجنبية يتجاوز عرض هذه العملة وفى هذه الحالة فان قيمة العملة المحلية تميل إلي الانخفاض مقارنه مع المعاملات الأخرى، التي تستخدم في المعاملات.ويحدث العكس في حاله الفائض أي أن الواردات البنكية اقل من الصادرات البنكية؛ فان في هذه الحالة يكون الطلب على العملة من طرف غير المقيمين أكثر أهمية من الطلب على ألأجنبية من طرف المقيمين وذلك يعنى زيادة الطلب على العملة المحلي وبتالي يرتفع سعر صرف العملة المحلية. من خلال الشكل رقم (5) الذي يوضح العلاقة بين المعاملات المصرفية الخارجية وسعر الصرف يمكن استنتاج ان سعر الصرف ترف يؤثر علي المعاملات المصرفية الخارجية حيث توجد علاقة تبادلية بين سعر الصرف والميزان التجاري البنكى .

\section{خايتمة الجزء الثاني:}

انطلاقا من مؤشرات الجزء الثاني تم التوصل الى وجود علاقة تبادلية بين سعر الصرف والمعاملات المصرفية الخارجية وتتمثل في أن أي فائض في المعاملات المصرفية الخارجية والناتج من زيادة قيمة الصادرات البنكية على قيمة الواردات البنكية عند حد معين فيؤدي ذلك إلى زيادة الطلب علي العملة الاجنبية في الاجل الطويل، مما يؤدي بدوره إلى ارتفاع سعر الصرف الاجنبي، ويؤدي استمرار ارتفاع سعر الصرف الاجنبي الي انخفاض حجم الصادرات البنكية الاجنبية لارتفاع اسعارها وبالتالي انخفاض حجم الطلب عليها.كما أن أي عجز في المعاملات المصرفية الخارجية للدولة ناتج عن زيادة قيمة الواردات البنكية على قيمة الصادرات البنكية، فإن ذلك يشير الي انخفاض قيمة 
العملة الاجنبية، ليؤدي في النهاية إلى ارتفاع سعر الصرف العملة المحلية(قيمة العملة المحلية) في الاجل الطويل ويؤدي انخفاض سعر صرف العملة الاجنبية الي زيادة الصادرات البنكية الاجنبية. اذن يكون هناك علاقة تبادلية بين سعر الصرف والمعاملات المصرفية الخارجية وان كلا منهما يؤثر علي الآخر، ويتحقق التوازن في كلا من المعاملات المصرفية الخارجية وسعر الصرف من خلال التوازن بين الصادرات البنكية والواردات البنكية حيث يعمل هذا التوازن علي استقرار مستوي اسعار الصرف ومنع تقلباته، لذا تتمثل الحالة المثلي في تحقيق توازن المعاملات المصرفية الخارجية وليس بوجود فائض او عجز في الميزان ،وتوجد علاقة عكسية بين الصادرات البنكية وسعر الصرف، وعلاقة عكسية بين الواردات البنكية وسعر الصرف وهذاعكس العلاقة النظرية بين سعر الصرف والواردات البنكية.

جدول رقم (4) : بيان عجز ميزان التجاري وعلاقته بسعر الصرف من (1986-2017)

\begin{tabular}{|c|c|c|c|c|c|}
\hline \multirow{2}{*}{ سعر الصرف } & رصيد الميزان & \multirow{2}{*}{ السنة } & \multirow{2}{*}{ سعر الصرف } & \multirow{2}{*}{ صالتجاري البنكى } & \multirow{2}{*}{ السنة } \\
\hline & $\begin{array}{c}\text { (واردات صادرات) } \\
\end{array}$ & & & & \\
\hline 3.97253 & -4.85085 & 2001 & 0.700001 & -12.1273 & 1986 \\
\hline 4.499667 & -4.35471 & 2002 & 0.700001 & -9.86286 & 1986 \\
\hline 5.850875 & -2.58683 & 2003 & 0.700001 & -10.2076 & 1987 \\
\hline 6.196242 & -1.35998 & 2004 & 0.700001 & -17.8427 & 1988 \\
\hline 7.778833 & -2.26555 & 2005 & 0.866667 & -14.4579 & 1989 \\
\hline 6.733167 & -1.61891 & 2006 & 1.55 & -12.6657 & 1990 \\
\hline 6.635433 & -4.57841 & 2007 & 3.138008 & -7.98009 & 1991 \\
\hline 8.432235 & -5.59464 & 2008 & 3.321748 & -2.51618 & 1992 \\
\hline 10.544553 & -6.6398 & 2009 & 3.352518 & -4.25258 & 1993 \\
\hline 12.621943 & -5.23786 & 2010 & 3.385133 & -5.48571 & 1994 \\
\hline 15.932828 & -4.12078 & 2011 & 3.392208 & -5.14706 & 1995 \\
\hline 16.056058 & -8.00435 & 2012 & 3.391483 & -5.449 & 1996 \\
\hline 16.870325 & -6.3944 & 2013 & 3.38875 & -6.05491 & 1997 \\
\hline 20.077609 & -8.54465 & 2014 & 3.388 & -9.49896 & 1998 \\
\hline 17.689548 & -7.51452 & 2015 & 3.39525 & -8.25748 & 1999 \\
\hline 17.691258 & -8.44102 & 2017 & 3.47205 & -6.6157 & 2000 \\
\hline
\end{tabular}

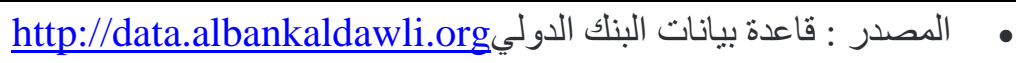

شكل رقم : (5) بيان عجز ميزان التجاري وعلاقته بسعر الصرف من (1986-2017)

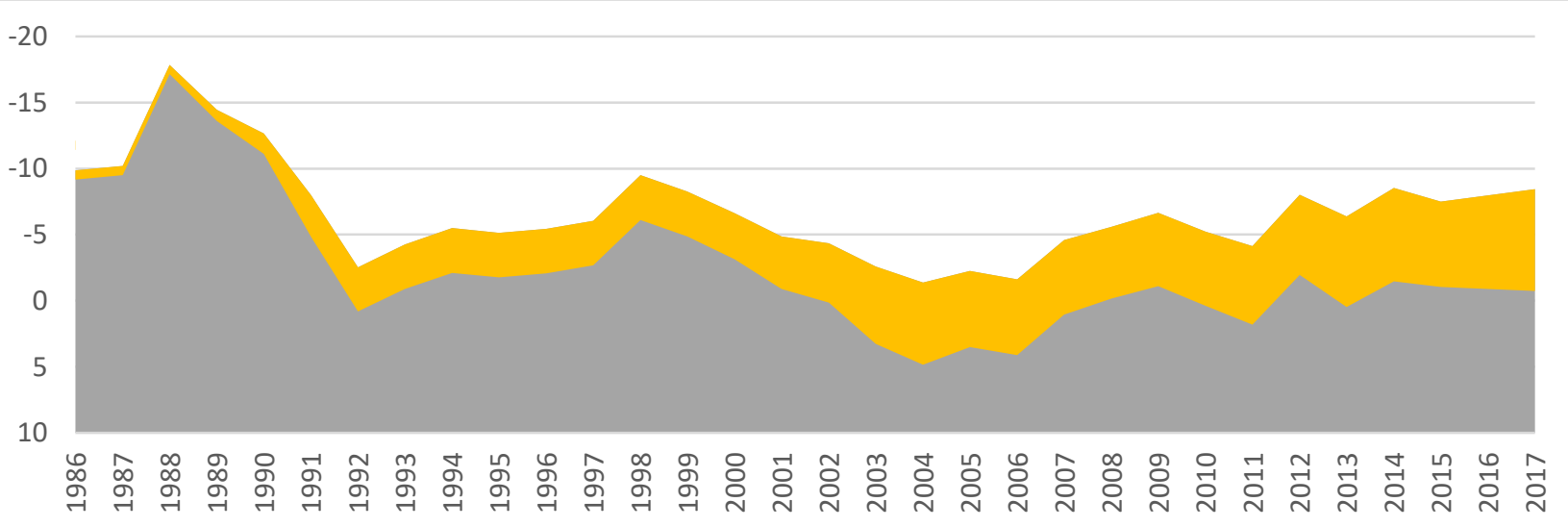


(4) المصدر : جدول رقم : (4)

ثالثا : تقدير دالة الإستثمار فى ضوء تعويم سعر الصرف :

أمكن دراسة بعض العوامل والمتغيرات المؤثرة على الإستثمارات الحقيقية فن مصر فن ضوء تعويم سعر الصرف ، كما هو موضح

بالجدول (1) بالملحق.

حيث تم توصيف نموذج قياسى يشتمل على بمموعة متغيرات مستقلة من المفترض أن يكون لها تأثير على الإستثمارات الحقيقية

$\gamma_{t}=\beta_{0}+\beta_{1} X_{1}+\beta_{2} X_{2}+\ldots \ldots \ldots \ldots \ldots+\beta_{13} X_{13}$

= • •

قيمة القروض الحقيقية بالمليار جنيه فن السنة (t).

ق قيمة الصادرات الحقيقية بالمليار جنيه في السنة (t).

• الدخل الحقيقى بالمليار جنيه فن السنة (t).

(t) اجمالى صافى الدخل الحقيقى بالمليار جنيه في السنة

•

• •

(t) السيولة المحلية الحقيقية بالمليار جنيه في السنة X7 •

•

• • عجز الميزان التجارى الحقيقى بالمليار جنيه فن السنة (t).

(t) الادخار المحلى الحقيقى باملليار جينه في السنة =

• سعر الصرف الحقيقى بالمليار جنيه في السنة (t).

(t) سعر الفائدة في السنة

(t) = سعر الخصم في السنة

ولقد تم حساب القيم الحقيقية وذلك بقسمة القيم الجارية على الرقم القياسى لأسعار في مصر. وبإجراء الحظطوات الحكيمة للوصول إلى Stepwise لأهم تلك العوامل المؤثرة في الإستثمارات تم التوصل إلى سيناريوهين: 
جدول (5): معادلتى الانحدار لأهم العوامل المؤثرة على الإستثمار المصرى

في ضوء تعويم سعر الصرف خلال الفترة (2000-2017)

\begin{tabular}{|c|c|c|c|c|}
\hline $\mathbf{F}$ & $\mathbf{R}^{-2}$ & المعادلة & البيان & p \\
\hline 105.6 & 0.93 & $\begin{array}{cc}\hat{Y}= & 0.63 \times 7-1.85 \times 9 \\
(7.5)^{* *} & (-3.3)^{* *} \\
\{11.6\} & \{-34.2\}\end{array}$ & السيناريو الأول & 1 \\
\hline 53.2 & 0.87 & $\begin{array}{cc}\hat{Y}=0.09 \times 3-3.4 \times 8 \\
(6.7)^{* *} & (-3.5)^{* *} \\
\{1.66\} & \{-66.6\}\end{array}$ & السيناريو الثانى & 2 \\
\hline
\end{tabular}

حيث: Y : القيمة التقديرية للإستثمار المصرى الحقيقى خلال الفترة (2000-2017).

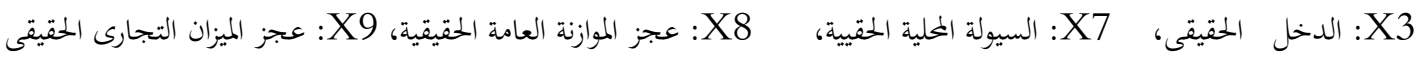

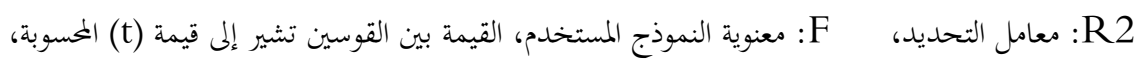

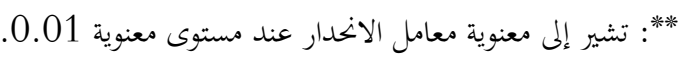

- الأرقام بين القوسين \} ك تشير إلى المرونات.

المصدر: حسبت من بيانات جدول (1) بالملحق.

ويتبين من تقدير الإستثمار تأثر الإستثمارات الحقيقة بكل من الدخل الحقيقى (X) بالمليار جنيه، والسيولة المحلية الحقيقية (X) بالمليار جنيه، وعجز الموازنة العامة الحقيقية (X) بالمليار جنيه، وعجز الميزان التجارى الحقيقى (X) بالمليار جنيه، وأيضاً أفضلية الصورة الخطية في التقدير وفقاً لمعيار معامل التحديد.

هذا وتوضح نتائج تقدير الإستثمارات (1) بجدول (5) معنوية النموذج إحصائياً عند مستوى 0.01، ويوضح معامل تحديد تلك المعادلة أن نحو 93\% من التغيرات الحادثة في الإستثمار الحقيقى ترجع إلى التغير في كل من السيولة المحلية الحقيقية وعجز الميزان التجارى الحقيقى، بينما ترجع باقى التغيرات إلى عوامل أخرى غير مقيسة بالدالة. وتوضح النتائج أن زيادة السيولة المحلية الحقيقية بمليار جنيه يؤدى إلى زيادة الإستثمارات الحقيقية بنحو 0.63 مليار جنيه، كما توضح أن زيادة عجز الميزان التجارى الحقيقى بمليار جنيه يؤدى إلى الخفاض الإستثمارات الحقيقية بنحو 1.85 مليار جنيه، وذلك مع ثبات العوامل الأخرى عند مستوى معين.

كما توضح نتائج تقدير المعادلة (2) بجدول (5) معنوية النموذج إحصائياً عند مستوى 0101، ويوضح معامل تحديد تلك المعادلة أن نحو 87\% من التغيرات الحادثة في الإستثمار الحقيقى ترجع إلى التغير في كل من الدخل الحقيقى، وعجز الموازنة العامة، بينما ترجع باقى التغيرات إلى عوامل أخرى غير مقيسة بالدالة.

وتوضح النتائج أن زيادة الدخل الحقيقى بمليار جنيه يؤدى إلى زيادة الإستثمارات الحقيقية بنحو 0.09 مليار جنيه، كما توضح أن زيادة عجز الموزانة العامة الحقيقية بمليار جنيه يؤدى إلى النفاض الإستثمارات الحقيقية بنحو 3.4 مليار جنيه، وذلك مع ثبات العوامل الأخرى عند مستوى معين. 
كما توضح نتائج المرونات فى المعادلة (1) بالجدول (5) أن زيادة السيولة المحلية الحقيقية بنسبة 1\% يؤدى إلى زيادة الإستثمارات الحقيقية بنسبة 11.6\%، وأن زيادة عجز الميزان التجارى الحقيقى بنسبة 1\% يؤدى إلى انخفاض الإستثمارات الحقيقية بمقدار 34.2\%. بينما توضح نتائج المرونات بالمعادلة (2) بالجدول (5) أن زيادة الدخل الحقيقى بنسبة 1\% يؤدى إلى زيادة الإستثمارات الحقيقية بنسبة 1.66\%، بينما زيادة عجز الموازنة العامة الحقيقية بنسبة 1\% يؤدى إلى الخفاض الإستثمارات الحقيقية بمقدار 66.6\%، وذلك مع ثبات العوامل الأخرى عند مستوى معين. وبذلك يتضح أن أكثر العوامل المؤثرة على زيادة الإستثمارات الحقيقية وفقاً للمرونات هى بالدرجة الأولى هى السيولة المحلية الحقيقية، يليها الدخل الحقيقى، فن حين تبين أن زيادة عجز الموازنة العامة الحقيقية مسئول بالدرجة الأولى عن الخفاض الإستثمارات الحقيقية، يليه زيادة عجز الميزان التجارى الحقيقى، وهى نتائج تتمشى مع المنطق الاقتصادى.

\section{النتائج والتوصيات}

$$
\text { اولا : النتائج }
$$

• هناك علاقة عكسية بين سعر الصرف الجنيه المصري والصادرات البنكية، بمعني إذا زاد سعر الصرف الجنيه المصري تقل الصادرات البنكية وهذا يؤثر بالسالب علي المعاملات المصرفية الخارجية أي يحدث عجز.وإذا حدث العكس فإنه يحدث فائض في الميزان

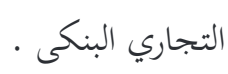
• هناك علاقة عكسية بين الواردات البنكية وسعر الصرف الجنيه المصري، وهذا علي عكس العلاقة الطبيعية بين الواردات البنكية وسعر الصرف الجنيه المصري وقد يرجع ذلك إلي عوامل أخري تؤثر علي الواردات البنكية بخلاف سعر الصرف.وتوجد العلاقة العكسية بين الواردات البنكية وسعر الصرف في حالة السلع الكمالية وهذا يخالف القاعدة العامة التي تنص علي"أن هناك علاقة طردية بين سعر الصرف والواردات البنكية" وهذا ما يحدث في السلع الضرورية مثل القمح. • ان سعر الصرف يؤثر علي المعاملات المصرفية الخارجية .

\section{ثانيا:التوصيات}

• ينغي علي الدولة أن تقوم بتخفيض سعر الفائدة الذي يؤدي بدوره إلي زيادة الاستثمارات حيث هناك علاقة عكسية بين الاستثمار وسعر الفائدة فعندما ينخفض سعر الفائدة هذا يشجع المستثمرين علي الاستثمار ومن ثم يزداد الناتج المحلي فتزداد الصادرات البنكية وفي مقابل ذلك يقل سعر الصرف. • علي الدولة المحافظة علي قيم الصادرات البنكية أن تتساوي أو تزيد عن قيم الواردات البنكية وذلك لمنع حدوث عجز في ميزان

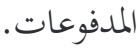
• ينبغي علي الدولة أن تزيد من المشروعات الصغيرة ،وتوفر فرص عمل للشباب حتى تزيد من الإنتاج فتقلل نسبة الواردات البنكية 
• زيادة الاحتياطات الدولية من النقد الاجنبى والحد من العجز في الميزان التجارى والموازنة العامة للدولة وترشيد الانفاق الحكومى من خلال اجراءات على المدى القصير والمتوسط. •عدم الاستمرارية في نظام التخفيض في سعر الصرف لانه يؤدى المى الاختلال فن ميزان المدفوعات. • محاربة السوق السوداء والمضاربين من خلال وضع قوانين اجرائية حمائية. • التركيز على السلع التى حققت مصر فيها ميزة تنافسية بحيث يتم تشجعيها بمزيد من المعاملة التفضيلية والحوافز وذلك لاستغلالها

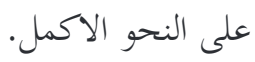
• توجيه الدعم للشركات التى تعمل على تحقيق اهداف التصدير من خلال رفع كفاءة العاملين بها عن طريق البرامج التدريبية المختلفة وتحسين جودة المنتج من خلال دعم البحوث والتطوير والابتكار. • اعفاء المصدرين الناجحين من الضريبة الغير مباشرة كما في حالة كوريا الجنوبية. • ربط الاعفاءات الضريبية بحصول المصدر على شهادة الجودة. • منح امتيازات للشركات التى تحصل على شهادة الجودة والمطابقة للمواصفات العالمية. • تطوير البنية التحتية بما يتفق مع متطلبات التصدير بما في ذلك النقل والشحن والاتصالات والكهرباء خاصة الاستثمار في تحسين خدمات الموانى البحرية والجوية. • ضرورة تضافر الجهود بين الحكومة والقطاع الخاص والمؤسسات التعليمية والبحثية والمجتمع المدنى للتغلب على المعوقات التى تحول دون تحقيق قفزة نوعية وكمية في الصادرات البنكية . • اعفاء الواردات البنكية الداخلة في تصنيع الصادرات البنكية من الضريبة الغير مباشرة كما في حالة تركيا. • ترشيد الواردات البنكية بما يتفق مع التزامات مصر الدولية من خلال ترشيد المشتريات الحكومية المستوردة.

المراجع

أولا: المراجع باللغة العربية الرسائل والابحاث • البنداري، عبدالوهاب خالد، "ثأثير الفروق في اسعار سعر صرف الجنيه المصري علي الاقتصاد المصري"، اتحاد الغرف التجارية، 2015.

• دوحة سلمي، اثر تقلبات سعر الصرف علي المعاملات المصرفية الخارجية وسبل علاجها "حالة الجزائر"، بحث مقدم لنيل شهادة الدكتوراة في العلوم التجارية، كلية العلوم الاقتصادية والتجارية وعلوم التسبير، جامعة محمد خيضر بسكرة، 2017. • اليامنة، الدواي، "اثر سعر الصرف علي التجارة الخارجية "حالة الجزائر" للفترة (1990-2014)" ، مذكرة مقدمة لاستكمال متطلبات شهادة ماستر اكاديمي، جامعة قاصدي مرباح، ورقلة، 2017. • شطباني، سعيدة، "محددات سعر صرف الدينار الجزائري ودوره في تحقيق الاستقرار الاقتصادي" دراسة قياسية اقتصادية لحالة الجزائر فترة (1993-2010)"، جامعة المسيلة، 2012. 
• الهنداوي عماد، علاقة أنظمة سعر الصرف بأداء الاقتصاد المصري، بحث مقدم لنيل رسالة دكتوراه الفلسفة في الاقتصاد، كلية التجارة، جامعة الزقازيق، 2011.

• خضر زاهر، تأثير سعر الصرف على المؤشرات الكلية للاقتصاد الفلسطيني، بحث مقدم لنيل درجة الماجستير، كلية الاقتصاد والعلوم الإدارية، جامعة الأزهر، 2011. • عبد الجليل هجيرة، أثر تغيرات سعر الصرف على الميزان التجاري البنكى، بحث مقدم لنيل درجة الدكتوراه، كلية العلوم الاقتصادية وعلوم التسيير، جامعة ابي بكر بلقايد، 2012. ثانياً: المراجع باللغة الأجنبية:

- (Boyared, and Caporale), "Real Exchange Rate Effects on the Balance of Trade, cointegration and the Marshal - Lerner condition",2017.

- Iman sugema,"THE DETERMINATION OF TRADE BALANCE AND ADJUSTMENT TO THE CRISIS IN INDONESIA, center for international economic studies, number 0508, 2015.

\section{الملحق}

جدول (1): تطور الإستثمار المصرى فى ضوء تعويم سعر الصرف وبعض المتغيرات ذات العلاقة به بالمليار جنيه وبالأسعار الحقيقية خلال الفترة (2000-2017)

\begin{tabular}{|c|c|c|c|c|c|c|c|c|c|c|c|c|c|c|}
\hline $\begin{array}{c}\text { سعر } \\
\text { \% } \\
\text { \% }\end{array}$ & $\begin{array}{c}\text { سعر الفائدة } \\
\text { \% } \\
\end{array}$ & الصرف & الالحلى & 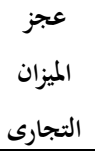 & الموازنة & الملية & الادخار & إنمالى & صافلى الدخل & الدخل & الصادرات & القروض & الإستثمار & \\
\hline 12.00 & 13.0 & 472 & 38.3 & 2.3 & 0.9 & 18.40 & 10.3 & 46.0 & 44.1 & 62.3 & 1.7 & 9.8 & 7.1 & 2000 \\
\hline 12.00 & 13.0 & 973 & 41.6 & 1.9 & 0.4 & 5.60 & 10.4 & 47.6 & 46.4 & 64.7 & 2.2 & 8 & .1 & 2001 \\
\hline 11.00 & 13.0 & 4.5 & 44.3 & 1.5 & 0.4 & 13.90 & 10.4 & 50.1 & 51.9 & 72.3 & 3.4 & 1.1 & .0 & 2002 \\
\hline 11.00 & 14.0 & 6.03 & 5.6 & 0.7 & 0.2 & 9.00 & 11.2 & 54.1 & 58.1 & 82.1 & 4.8 & 0. & J.T & 2003 \\
\hline 10.00 & 13.0 & 6.19 & 63.9 & 0.7 & 0.3 & 9.60 & 11.9 & 58.5 & 69.5 & 94.3 & 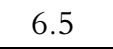 & 10.8 & 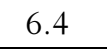 & 2004 \\
\hline 10.00 & .13 & 5.78 & 67.4 & 1.3 & 0.4 & 11.80 & 13.6 & 59.9 & 74.0 & 101.1 & 4.9 & 23. & 5.9 & 2005 \\
\hline 10.00 & 13.0 & 5.75 & 1.9 & 0.9 & 1.1 & 13.14 & 15.9 & 63.4 & 79.4 & 106.5 & 4.6 & 26.1 & 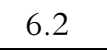 & 2006 \\
\hline 9.00 & 13.0 & 5.69 & 83.7 & 1.3 & 1.2 & 14.10 & 16.7 & 69.0 & 80.3 & 107.7 & 5.6 & 1. & 5.4 & 2007 \\
\hline 9.00 & 13.0 & 5.34 & 93.3 & 3.2 & 1.5 & 17.10 & 17.4 & 72.0 & 8.7 & 118.2 & 8.6 & 5.9 & 5.1 & 2008 \\
\hline 10.50 & 12.0 & 5.6 & 77.9 & 2.2 & 1.4 & 16.00 & 18.2 & 81.7 & 83.3 & 114.2 & 11.5 & 10.7 & 4.1 & 2009 \\
\hline 9.13 & 12.0 & 5.7 & 98.6 & 2.6 & 1.7 & 16.20 & 18.9 & 92.2 & 86.3 & 119.9 & 12.5 & 9.8 & 3.9 & 2010 \\
\hline 8.50 & 11.0 & 5.96 & 98.7 & 2.3 & 2.1 & 15.50 & 19.1 & 103.8 & 98.0 & 136.4 & 12.3 & 0.3 & 3.1 & 2011 \\
\hline 8.75 & 11.0 & 6.05 & 83.7 & 3.5 & 2.4 & 15.60 & 20.0 & 113.6 & 99.4 & 139.3 & 14.0 & 8.9 & 2.8 & 2012 \\
\hline 8.75 & 11.0 & 7.01 & 68.2 & 2.6 & 2.5 & 13.10 & 20.6 & 121.2 & 101.5 & 140.7 & 17.0 & 10.1 & 1.2 & 2013 \\
\hline 9.50 & 12.6 & 7.15 & 90.2 & 3.1 & 2.4 & 14.2 & 21.2 & 132.1 & 106.8 & 145.8 & 19.2 & 10.5 & 5.6 & 2014 \\
\hline 8.75 & 11.0 & 7.01 & 68.2 & 2.6 & 2.5 & 13.10 & 20.6 & 121.2 & 101.5 & 140.7 & 17.6 & 10.1 & 4.2 & 2017 \\
\hline 9.50 & 12.6 & 7.15 & 90.2 & 3.1 & 2.4 & 14.2 & 21.2 & 132.1 & 106.8 & 145.8 & 19.2 & 10.5 & 0.0 & 2017 \\
\hline 9.91 & 12.2 & 5.6 & 72.2 & 2.0 & 1.3 & 13.24 & 15.7 & 77.7 & 77.7 & 107.0 & 8.6 & 11.0 & 5.4 & المتوسط \\
\hline
\end{tabular}


1-الجهاز المركزى للتعبئة العامة والإحصاء، نشرة التجارة الخارجية، أعداد متفرقة.

2-وزارة التنمية الاقتصادية، خطة التنمية الاقتصادية والاجتماعية، أعداد متفرقة. 